\title{
A Meta-analysis on Vitamin D Deficiency in Patients with Sickle Cell Disease
} \author{
Malaz Ahmed Osman Elsayed ${ }^{3}$ \\ ${ }^{1}$ Department of Paediatrics and Child Health, Faculty of Medicine, University of Khartoum, Sudan \\ ${ }^{2}$ Institute of Endemic Diseases, Faculty of Medicine, University of Khartoum, Sudan \\ ${ }^{3}$ Department of Internal Medicine, Faculty of Medicine, University of Khartoum, Sudan \\ ${ }^{4}$ Department of Surgery, Faculty of Medicine, Shendi University, Sudan \\ ${ }^{5}$ Education Development Center, Faculty of Medicine, University of Khartoum, Sudan
}

Sagad Omer Obeid Mohamed ${ }^{1,}$, (D), Fatima Abdelhakam Abdellatif MohamedElmugadam², Hiba Faroug Mohamed Awadalla ${ }^{3}$, Abdalla Omer Obeid Mohamedali ${ }^{4}$, Mansour Osman Alhaj Alawad ${ }^{1}$, Ahmed Abdulgadir Noureddin ${ }^{1}$, Afnan Abugundul Ahmed Osman², Esraa Mohamed Osman Mohamed', Gehad Abdelmonem Abdalla Ibrahim5,

\section{ARTICLE INFO}

\section{Article History}

Received 28 February 2020

Accepted 05 July 2020

\section{Keywords}

Vitamin D

sickle cell disease

meta-analysis

\begin{abstract}
Vitamin D Deficiency (VDD) is reported to be more frequent with serious clinical outcomes in patients with Sickle Cell Disease (SCD). There is a wide disparity in data in the existing literature regarding the prevalence and risk of VDD in patients with SCD. These data require further summary and analyses for better accuracy. This review aimed to assess the association between VDD and SCD, and was conducted according to the Preferred Reporting Items for Systematic Reviews and Meta-Analyses guidelines. Medline/ PubMed, World Health Organization Virtual Health Library, ScienceDirect, and Google Scholar were used for the systematic search. A random effects model was used to estimate the pooled prevalence, Risk Ratio (RR), and Standardized Mean Difference (SMD) estimates with the corresponding 95\% Confidence Interval (CI) using OpenMeta Analyst software version 10.10 (Tufts Medical Center, Boston, MA, USA). Twenty-five studies fulfilled the eligibility criteria. The prevalence of VDD among patients with SCD was $63.8 \%$ (95\% CI, 52.5-75.1). The risk of VDD among patients with SCD was more than two times that of the general population $(\mathrm{RR}=2.129 ; 95 \% \mathrm{CI}, 1.024-4.423 ; p<0.001)$. Serum vitamin D levels were significantly lower in SCD patients than in their controls $(\mathrm{SMD}=-1.883: 95 \% \mathrm{CI},-3.006$ to $-0.760 ; p<0.001)$. This review provides a comprehensive view of the association between vitamin D status and SCD.
\end{abstract}

(C) 2020 Dr. Sulaiman Al Habib Medical Group. Publishing services by Atlantis Press International B.V. This is an open access article distributed under the CC BY-NC 4.0 license (http://creativecommons.org/licenses/by-nc/4.0/).

\section{INTRODUCTION}

Vitamin D is essential for normal development and maintenance of healthy bone in pediatric and adult populations, as well as the regulation of the immune system functions and inflammatory responses $[1,2]$. Recently, Vitamin D Deficiency (VDD) has become of public health importance as it contributes to adverse clinical manifestations [1]. In addition to rickets and bone disorders, VDD is related to several other health disorders such as cardiovascular diseases, asthma, infectious diseases, muscle weakness, diabetes mellitus, autoimmune thyroid diseases, and several malignancies [1-4].

Sickle Cell Disease (SCD) is one of the most common inherited disorders worldwide [5]. Several different genotypes cause SCD, although all include the $\mathrm{HbS}$ allele, the homozygous inheritance of the mutated beta S-globin chains (HbSS) is the most common form that refers to conditions characterized by the production of sickle hemoglobin, leading to a cascade of pathophysiological

"Corresponding author.Email: s.oom123@yahoo.com

Peer review under responsibility of the Dr. Sulaiman Al Habib Medical Group

Data availability statement: The dataset generated during this study are available from the corresponding author on reasonable request. consequences including infarction, hemolysis, oxidative stress, hypercoagulability, and inflammation [5-7]. SCD is associated with protean clinical presentations such as chronic hemolytic anemia, painful crisis, acute chest syndrome, sequestration crisis, aplastic crisis, and acute cerebrovascular accidents [5-9].

Several studies have revealed that patients with SCD are at risk of multiple macro- and micronutritional deficiencies, and they have a higher prevalence and risk of VDD regardless of their age or ethnic background [10-12]. Several studies have explored the risk factors influencing vitamin D status, such as limitation of exposure to natural light, which affects vitamin D biosynthesis; dark skin, which acts as a natural barrier to UV irradiation penetrating the skin; obesity and high body mass index, in which adipose tissues sequester vitamin D; and poor dietary intake of vitamin D [13-15].

Since vitamin D is involved in the regulation of calcium level and bone health, its deficiency could further impair bone comorbidity and contribute to the musculoskeletal disorders already present in patients with SCD $[11,12,16]$. A recent study has investigated the association of vitamin D status with inflammatory parameters and anti-inflammatory cytokines in patients with SCD, and showed the contribution of VDD to the uncontrolled, chronic inflammation 
and concurrent vaso-occlusion seen in the course of SCD [17]. Low serum vitamin $\mathrm{D}$ is associated with an increased level of proinflammatory cytokines and diminished level of anti-inflammatory cytokines when compared with healthy non-SCD individuals, and the levels also differ in SCD patients with vaso-occlusive crisis and those in steady state [18].

Moreover, some people with SCD who were treated for VDD had less painful crises than those who are not treated [18]. Also, recent trials suggest the potential benefit of vitamin $\mathrm{D}$ supplementation on the resolution of chronic pain symptoms, reducing the number of days with pain, and reduced use of analgesics [19]. It is reported that vitamin $\mathrm{D}$ supplementation can suppress proinflammatory cytokines such as interleukin (IL)- 6 and tumor necrosis factor- $\alpha$ and upregulate the synthesis of the anti-inflammatory cytokine IL-10 [18]. A trial in SCD patients showed the significant effect of 3 months' daily vitamin D supplementation in reducing the levels of proinflammatory cytokines IL-2, 6, 8, 17, and 18, and increasing the level of anti-inflammatory cytokine IL-11 [18].

Previous studies of VDD in patients with SCD have shown inconsistent, variable data. A previous systematic review found that VDD was highly prevalent among patients with SCD [20]. To the best of our knowledge, there is no meta-analysis of existing evidence on the various aspects of the association between SCD and VDD. These data require further summary and analyses for better accuracy. The results of this meta-analysis provide a comprehensive view and may contribute to better management of SCD.

\section{MATERIALS AND METHODS}

\subsection{Search Strategy and Inclusion Criteria}

The methodology was developed from the Preferred Reporting Items for Systematic Reviews and Meta-Analyses statement [21]. A systematic literature search was performed using the electronic databases of Medline/PubMed, Google Scholar, World Health Organization Virtual Health Library, and ScienceDirect. The search terms used were "vitamin D", "hydroxycholecalciferol", "25-hydroxyvitamin D", "25-hydroxycholicalciferol", "cholecalciferol", and "sickle cell" to ensure no possible relevant articles were missed. Also, we reviewed the articles referenced by those identified articles in this search.

The inclusion criteria were: (1) cross-sectional, case-control, or cohort studies that assessed the prevalence and/or association between VDD and SCD or its complications; (2) studies with sufficient data for calculation of prevalence, Risk Ratio (RR), and/or Standardized Mean Difference (SMD) estimates; and (3) studies published in English up to November 2019. Studies were considered relevant if they assessed one or more of the following: prevalence of VDD amongst SCD patients; risk of developing VDD among SCD patients; and mean level of 25-hydroxyvitamin D among SCD patients compared to their controls.

We excluded case reports, editorials, letters, abstracts, and studies without sufficient data of interest. If two or more studies had the same patient population, the recent study with more complete data was included to avoid duplication.

The titles and abstracts of all articles retrieved from this search were screened for potential inclusion in this review. Then, studies deemed to be relevant were reviewed (full text) for inclusion according to the defined eligibility criteria. Quality of the included studies was assessed using the Newcastle-Ottawa Scale; a tool that determines the quality based on the selection of the study group, comparability of groups, and ascertainment of the exposure and outcomes [22].

Three independent reviewers extracted the relevant information using a designed data extraction form and any disparity among the reviewers was resolved by discussion and consensus. For qualitative and quantitative data synthesis, we extracted the following information from each article: authors; year of publication; study region; study design; primary aim of the study; strengths/additional findings of the study; main limitations of the study; age groups of the participants; reference level used for definition of VDD and/or severe VDD; number of SCD patients; number of controls (if present); number of SCD patients with VDD; number of controls with VDD (if present); and mean serum level of 25-hydroxyvitamin D with their corresponding SD values.

\subsection{Statistical Analysis}

The statistical analyses were carried out using OpenMeta Analyst software version 10.10 [23]. The pooled summary prevalence, RR, and SMD were calculated from the random-effects model due to the notable heterogeneity. Statistical heterogeneity was assessed with the $I^{2}$ statistics and the $I^{2}$ values of $25 \%, 50 \%$, and $75 \%$ were related to low, moderate, and high heterogeneity, respectively.

We conducted subgroup and meta-regression analyses to investigate the potential sources of heterogeneity and to determine the extent to which variables of interest moderated the overall results. The Chi-square test was used to assess the differences between the categorical subgroups and the significance level was set at 0.05. Publication bias was determined through Begg's test, Egger's test, and visual examination of the funnel plot [24,25].

According to the literature review [26,27] and the reference values used for defining VDD by most of the included studies, we considered a 25 -hydroxyvitamin D serum level $<20 \mathrm{ng} / \mathrm{mL}(<50 \mathrm{nmol} / \mathrm{L})$ as VDD. In addition, we considered a 25-hydroxyvitamin D serum level $<10 \mathrm{ng} / \mathrm{mL}$ as severe VDD in this analysis.

\section{RESULTS}

\subsection{Studies Included}

The schematic flow of study identification and selection process is presented in Figure 1, and the main features of the included studies are shown in Tables S1 and S2. Our search retrieved records for 490 published articles. Full texts of 40 studies were screened, and 15 studies were subsequently excluded because of insufficient data to estimate the outcomes of interest (Figure 1). A total of 25 studies published from 1993 to 2019 that met the eligibility for data were used for qualitative and quantitative syntheses: 10 studies from the Americas [12,28-36]; six studies from Asia [37-42]; five studies from Europe [43-47]; two studies from Africa $[48,49]$, one study that used samples from both Jamaica and West Africa [50], and one study that used samples from both Brazil and Nigeria [51]. 


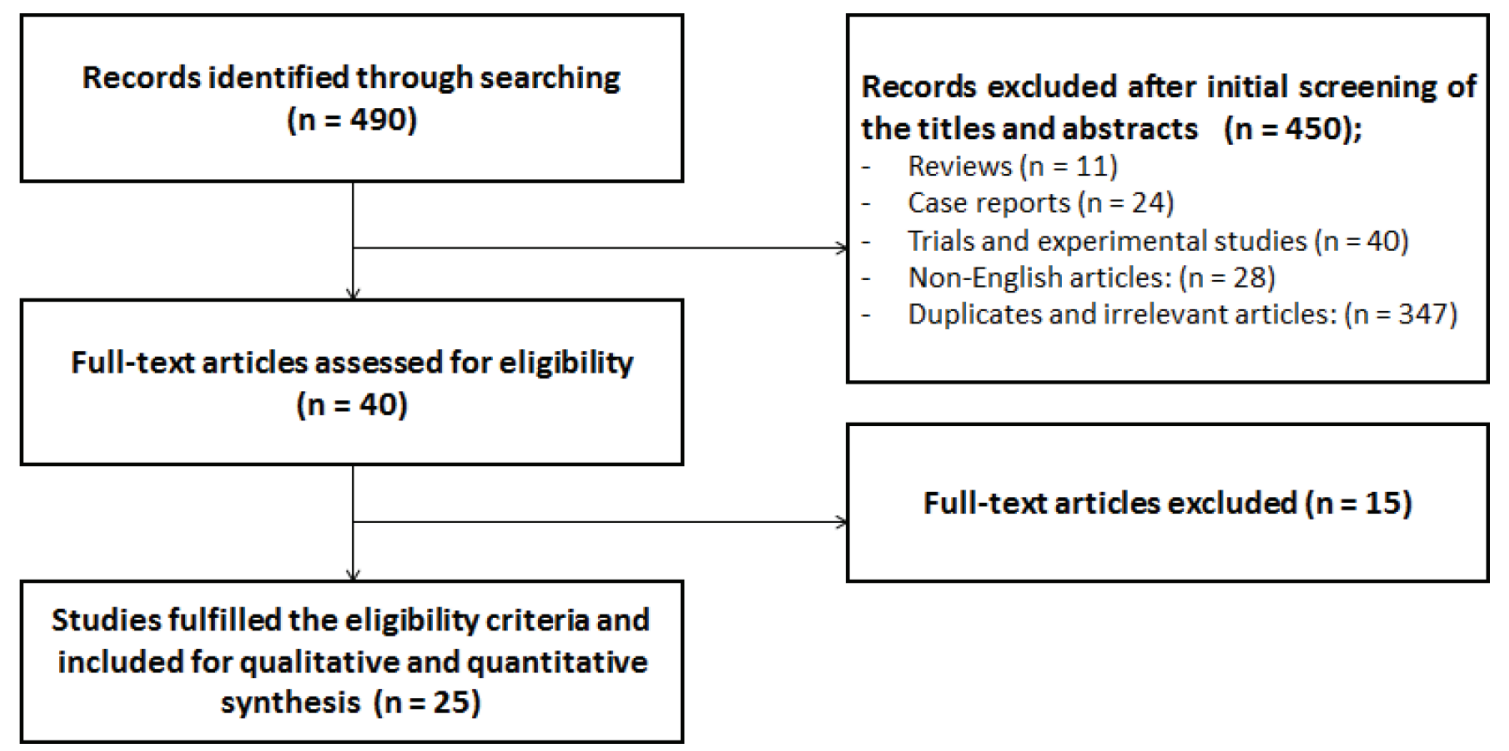

Figure $1 \mid$ Flow chart for study selection process.

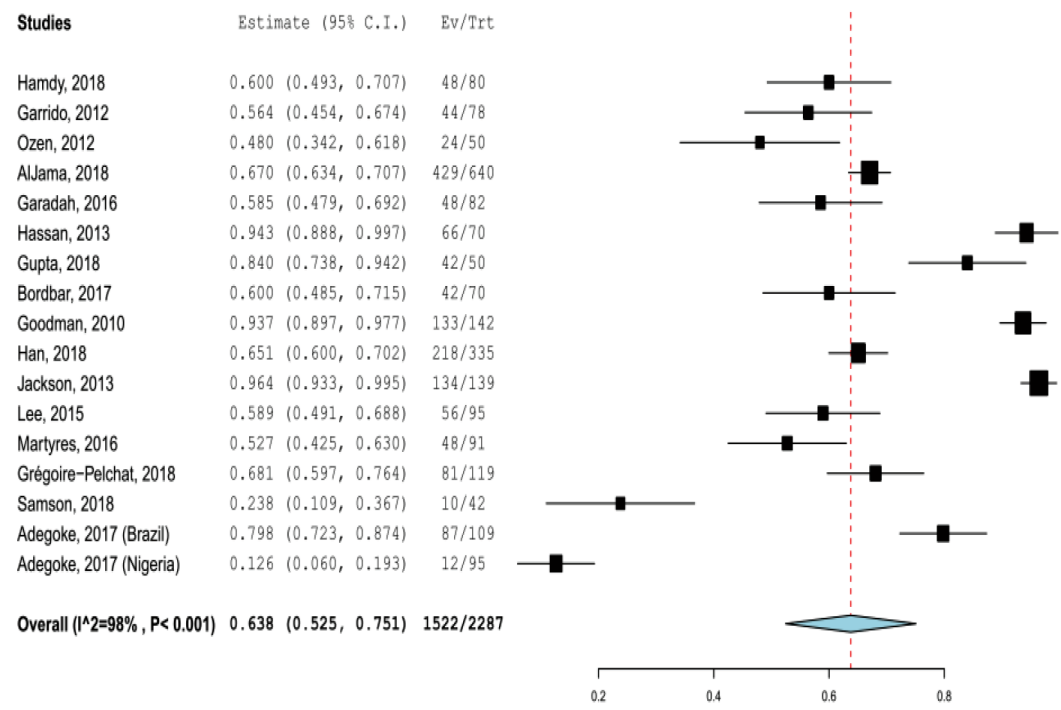

Figure 2 Pooled prevalence of vitamin D deficiency in patients with sickle cell disease.

\subsection{Prevalence of VDD among Patients with SCD}

Most of the included studies (16 of 25 studies) provided sufficient data about VDD in patients with SCD based on serum level of 25-hydroxyvitamin $\mathrm{D}<20 \mathrm{ng} / \mathrm{mL}(50 \mathrm{nmol} / \mathrm{L})$. Based on that definition, the pooled prevalence of VDD in patients with SCD was 63.8\% (52.5-75.1\%) (Figure 2). No evidence of publication bias was detected based on visual examination of the funnel plot and from the results of Begg's test $(p=0.31)$ and Egger's test $(p=0.40)$. There were 10 studies with sufficient data to estimate the prevalence of severe VDD based on serum level of 25 -hydroxyvitamin $\mathrm{D}<10 \mathrm{ng} / \mathrm{mL}(25 \mathrm{nmol} / \mathrm{L})$. The pooled prevalence of severe VDD in patients with SCD was $27.0 \%$ (95\% CI, 15.9-38.0).
In subgroup analysis based on age groups, there were 14 studies of children with SCD and the pooled prevalence of VDD was 56.2\% (36.7-75.7). The pooled prevalence of VDD from the seven studies of adults with SCD was 75.5\% (57.5-93.5). The prevalence of VDD was significantly associated with age groups $\left(\chi^{2}=28.3, p<0.001\right)$. The meta-regression showed that publication year was not correlated with the prevalence of VDD (coefficient $=-0.024, p=0.134$ ).

\subsection{Risk of VDD among Patients with SCD Compared to the General Population}

There were five studies with sufficient data to calculate the risk of having VDD among patients with SCD compared to the general population. The pooled RR of VDD from the random-effects model was 2.129 (95\% CI, 1.024-4.423) for patients with SCD 


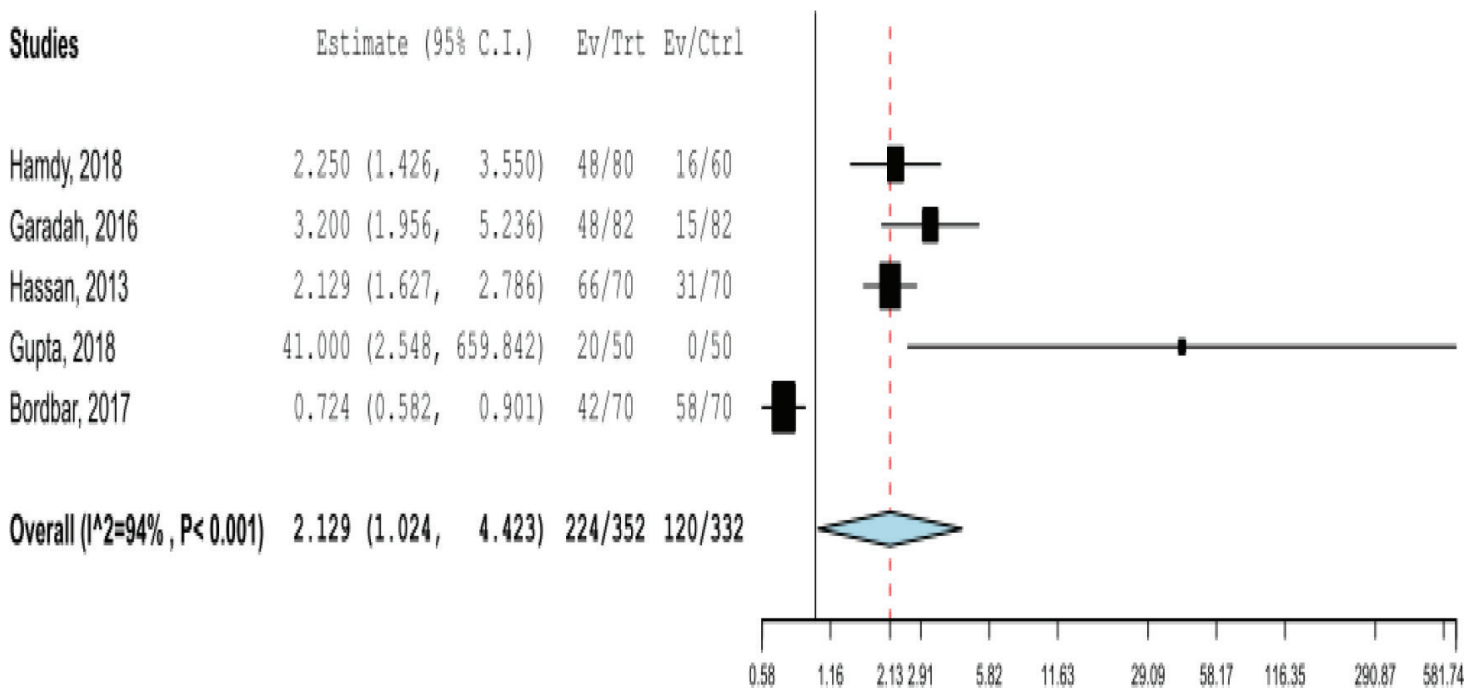

Figure 3 Pooled risk ratio of having vitamin D deficiency in patients with sickle cell disease.

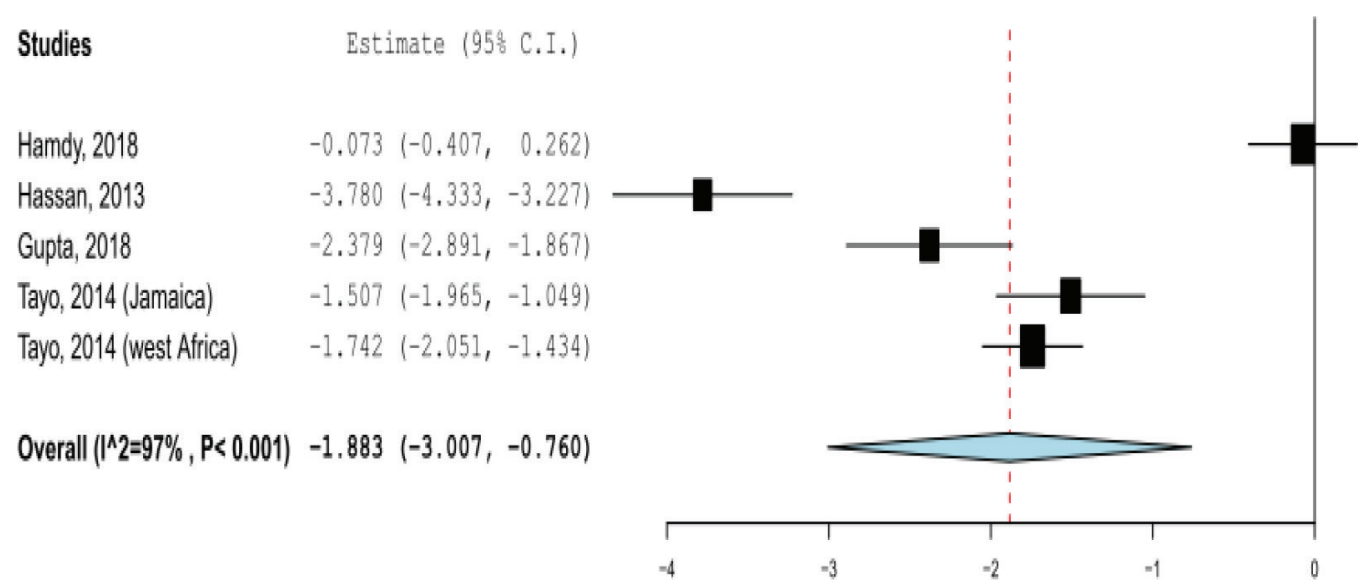

Figure 4 Pooled standardized mean difference of 25-hydroxyvitamin D estimates between patients with sickle cell disease and their controls.

compared with the general population (Figure 3). Publication bias was detected based on the visual examination of the funnel plot.

\subsection{SMD of Serum 25-Hydroxyvitamin D Level}

There were four studies (including five study groups) with sufficient data to calculate the SMD of 25-hydroxyvitamin D estimates between patients with SCD and their controls. The pooled effect size showed that the serum 25-hydroxyvitamin D levels in SCD patients were significantly lower than their controls, with SMD $=-1.883$ (95\% CI, -3.006 to $-0.760 ; p<0.001$ ) (Figure 4 ). No evidence of publication bias was detected on visual examination of the funnel plot and from the results of Begg's test $(p=0.35)$ and Egger's test $(p=0.32)$.

\section{DISCUSSION}

In this review, we have an updated estimate of the global prevalence of VDD in patients with SCD. A spectrum of definitions of VDD has been reported in the literature based on serum level of 25-hydroxyvitamin $\mathrm{D}$, which is considered the most accurate marker for vitamin D status [2,4,26,27]. However, most of the included studies in this review used the definition of VDD as serum level of 25 -hydroxyvitamin $\mathrm{D}<20 \mathrm{ng} / \mathrm{mL}$ ( $50 \mathrm{nmol} / \mathrm{L}$ ), which is a common definition in the literature [4], and it is consistent with the definition of VDD based on the reports of The United States Endocrine Society, American Academy of Pediatrics, and Institute of Medicine [1].

Existing evidence from the reviewed studies shows that $63.8 \%$ of the SCD patients had VDD, and $27.0 \%$ of them had severe VDD. We have found that the prevalence of VDD is higher in adults than in children. This pattern of a relationship with age is well established $[28,31,36]$. However, it is unclear that VDD follows a specific geographical pattern because it is a global health problem. Moreover, variation was found between studies conducted within the same country as noted in the American and Canadian studies included in this analysis.

We did not analyze four studies identified during our search in this meta-analysis because of the different cut-off points of VDD used $[12,28,31,38]$. Rovner et al. [12] found that $33 \%$ of patients with SCD had 25 -hydroxyvitamin $\mathrm{D}<11 \mathrm{ng} / \mathrm{mL}$ and the risk of VDD among 
patients with SCD was more than five times greater than in the controls. Buison et al. [28] found that $65 \%$ of the included children with SCD had low vitamin D status based on 25-hydroxyvitamin $<11 \mathrm{ng} /$ $\mathrm{mL}(27.5 \mathrm{nmol} / \mathrm{L})$, and showed that children with SCD were at higher risk for low vitamin D status than healthy children were. Winters et al. [36] detected VDD in 32\% of pediatric SCD patients and $49 \%$ of adult SCD patients, based on serum 25 -hydroxyvitamin $<11 \mathrm{ng} / \mathrm{mL}$. Chapelon et al. [43] assessed VDD in French children with SCD and found that $76 \%$ of them had 25 -hydroxyvitamin $<12 \mathrm{ng} / \mathrm{mL}$.

Several peculiar characteristics of SCD could explain the high prevalence and increased risk of VDD among patients with SCD, such as: impaired absorption by the damaged intestinal mucosa as a complication of SCD; decreased level of vitamin D binding protein due to the inflammatory condition in SCD; increased physiological demands due to the fast turnover in the process of erythrocytosis in SCD; and reduced levels of nutritional status, physical activity, and exercise in patients with SCD [12,28,30,40,44,46,49].

A few of the reviewed studies assessed the correlation between vitamin D status and SCD-related health complications. Hamdy et al. [49] showed a significant correlation between serum vitamin $\mathrm{D}$ level and the biomarkers of hemolysis (lower level of hemoglobin and a higher level of aspartate aminotransferase, lactate dehydrogenase, and bilirubin), and the clinical course and complications of SCD (frequency of blood transfusions and hospitalization, occurrence of vaso-occlusive crises, and recurrent infections). Similarly, Mandese et al. [44] demonstrated the significant negative correlation between levels of vitamin D and clinical indicators of the SCD severity (hospitalization and number of days of hospital admissions). A similar association between the VDD and the vaso-occlusive crisis of SCD was shown also by Lee et al. [32] and Gupta and Katariya [40]. By contrast, some of the included studies did not find a significant association between VDD and these complications $[28,31,47]$.

The findings of this study need to be considered in the context of some limitations. The inclusion of studies published only in English may have compromised representativeness. We could not assess the association between VDD and SCD-related health complications because of the data limitation and heterogeneity among the included studies. Also, we could not assess the possible risk factors of VDD among patients with SCD. Data on SMD and risk of VDD among patients with SCD were obtained from few studies. There is still a need for large prospective studies with appropriate controls to assess the unanswered questions in this study.

\section{CONCLUSION}

We have summarized data of several studies exploring the vitamin D status in patients with SCD. VDD occurs with increased frequency in patients with SCD. The results of this study could have important implications and provide a reference for the management of patients with SCD. Healthcare providers need to be aware of the clinically important association between VDD and SCD to ensure effective management.

\section{CONFLICTS OF INTEREST}

The authors declare they have no conflicts of interest.

\section{AUTHORS' CONTRIBUTION}

SM conceptualized the research idea. SM, FM, HA, AO and EM undertook database searches. SM and AM undertook data extraction and analysis. SM, MA, AN, GI and ME interpreted the results and drafted the manuscript. All authors revised, read, and approved the final manuscript.

\section{SUPPLEMENTARY MATERIALS}

Supplementary data related to this article can be found at https:// doi.org/10.2991/dsahmj.k.200717.001.

\section{REFERENCES}

[1] Liu X, Baylin A, Levy PD. Vitamin D deficiency and insufficiency among US adults: prevalence, predictors and clinical implications. Br J Nutr 2018;119;928-36.

[2] Dougherty KA, Bertolaso C, Schall JI, Smith-Whitley K, Stallings VA. Safety and efficacy of high dose daily vitaminD $\mathrm{D}_{3}$ supplementation in children and young adults with sickle cell disease. J Pediatr Hematol Oncol 2015;37;e308-e15.

[3] Ariganjoye R. Pediatric hypovitaminosis D: molecular perspectives and clinical implications. Glob Pediatr Health 2017;4;2333794X16685504.

[4] Prietl B, Treiber G, Pieber TR, Amrein K. Vitamin D and immune function. Nutrients 2013;5;2502-21.

[5] Chakravorty S, Williams TN. Sickle cell disease: a neglected chronic disease of increasing global health importance. Arch Dis Child 2015;100;48-53.

[6] Brousse V, Makani J, Rees DC. Management of sickle cell disease in the community. BMJ 2014;348;g1765.

[7] Jastaniah W. Epidemiology of sickle cell disease in Saudi Arabia. Ann Saudi Med 2011;31;289-93.

[8] Wastnedge E, Waters D, Patel S, Morrison K, Goh MY, Adeloye $\mathrm{D}$, et al. The global burden of sickle cell disease in children under five years of age: a systematic review and meta-analysis. J Global Health 2018;8;021103.

[9] Ricerca BM, Di Girolamo A, Rund D. Infections in thalassemia and hemoglobinopathies: focus on therapy-related complications. Mediterr J Hematol Infect Dis 2009;1;e2009028.

[10] Kawchak DA, Schall JI, Zemel BS, Ohene-Frempong K, Stallings VA. Adequacy of dietary intake declines with age in children with sickle cell disease. J Am Diet Assoc 2007;107;843-8.

[11] Hyacinth HI, Gee BE, Hibbert JM. The role of nutrition in sickle cell disease. Nutr Metab Insights 2010;3;57-67.

[12] Rovner AJ, Stallings VA, Kawchak DA, Schall JI, OheneFrempong K, Zemel BS. High risk of vitamin D deficiency in children with sickle cell disease. J Am Diet Assoc 2008; 108;1512-16.

[13] Parva NR, Tadepalli S, Singh P, Qian A, Joshi R, Kandala H, et al. Prevalence of vitamin D deficiency and associated risk factors in the US population (2011-2012). Cureus 2018;10;e2741.

[14] Kumaratne M, Early G, Cisneros J. Vitamin D deficiency and association with body mass index and lipid levels in Hispanic American adolescents. Glob Pediatr Health 2017;4;2333794X17744141.

[15] Correia A, Azevedo Mdo S, Gondim F, Bandeira F. Ethnic aspects of vitamin D deficiency. Arq Bras Endocrinol Metab $2014 ; 58 ; 540-4$. 
[16] McCaskill ML, Ogunsakin O, Hottor T, Harville EW, Kruse-Jarres R. Serum 25-hydroxyvitamin D and diet mediates vaso-occlusive related hospitalizations in sickle-cell disease patients. Nutrients 2018;10;1384.

[17] Oztas Y, Unal S, Eskandari G, Tamer L, Ozgunes N. Vitamin D deficiency and its association with inflammatory markers, lipid profile and regulatory T-cells in pediatric sickle cell disease patients. Indian J Hematol Blood Transfus 2018;34;480-5.

[18] Adegoke SA, Smith OS, Adekile AD, Figueiredo MS. Relationship between serum 25-hydroxyvitamin D and inflammatory cytokines in paediatric sickle cell disease. Cytokine 2017;96;87-93.

[19] Soe HHK, Abas AB, Than NN, Ni H, Singh J, Said ARBM, et al. Vitamin D supplementation for sickle cell disease. Cochrane Database Syst Rev 2017;1;CD010858.

[20] Nolan VG, Nottage KA, Cole EW, Hankins JS, Gurney JG. Prevalence of vitamin D deficiency in sickle cell disease: a systematic review. PLoS One 2015;10;e0119908.

[21] Liberati A, Altman DG, Tetzlaf J, Mulrow C, Gøtzsche PC, Ioannidis JP, et al. The PRISMA statement for reporting systematic reviews and meta-analyses of studies that evaluate health care interventions: explanation and elaboration. J Clin Epidemiol 2009;62;e1-e34.

[22] Wells GA, Shea B, O'Connell D, Peterson J, Welch V, Losos M, et al. The Newcastle-Ottawa Scale (NOS) for assessing the quality of nonrandomised studies in meta-analyses. Ottawa, ON, Canada: The Ottawa Hospital Research Institute; 2013. Available from: http://www.ohri.ca/programs/clinical_epidemiology/oxford.asp

[23] Wallace BC, Dahabreh IJ, Trikalinos TA, Lau J, Trow P, Schmid $\mathrm{CH}$. Closing the gap between methodologists and end-users: $\mathrm{R}$ as a computational back-end. J Stat Softw 2012;49;1-15.

[24] Borenstein M, Hedges LV, Higgins JPT, Rothstein HR. A basic introduction to fixed-effect and random-effects models for meta-analysis. Res Synth Methods 2010;1;97-111.

[25] Begg CB, Mazumdar M. Operating characteristics of a rank correlation test for publication bias. Biometrics 1994;50;1088-101.

[26] Holick MF. Vitamin D deficiency. N Engl J Med 2007;357;266-81.

[27] Holick MF. Vitamin D status: measurement, interpretation, and clinical application. Ann Epidemiol 2009;19;73-8.

[28] Buison A, Kawchak DA, Schall J, Ohene-Frempong K, Stallings VA, Zemel BS. Low vitamin D status in children with sickle cell disease. J Pediatr 2004;145;622-7.

[29] Goodman BM, Artz N, Radford B, Chen IA. Prevalence of vitamin D deficiency in adults with sickle cell disease. J Natl Med Assoc 2010;102;332-5.

[30] Han J, Zhang X, Saraf SL, Gowhari M, Molokie RE, Hassan J, et al. Risk factors for vitamin D deficiency in sickle cell disease. Br J Haematol 2018;181;828-35.

[31] Jackson TC, Krauss MJ, DeBaun MR, Strunk RC, Arbeláez AM. Vitamin D deficiency and comorbidities in children with sickle cell anemia. Pediatr Hematol Oncol 2012;29;261-6.

[32] Lee M, Licursi M, McMahon DJ. Vitamin D deficiency and acute vaso-occlusive complications in children with sickle cell disease. Pediatr Blood Cancer 2015;62;643-7.

[33] Martyres DJ, Vijenthira A, Barrowman N, Harris-Janz S, Chretien C, Klaassen RJ. Nutrient insufficiencies/deficiencies in children with sickle cell disease and its association with increased disease severity. Pediatr Blood Cancer 2016;63;1060-4.

[34] Grégoire-Pelchat P, Alos N, Ribault V, Pastore Y, Robitaille N, Mailhot G. Vitamin D intake and status of children with sickle cell disease in Montreal, Canada. J Pediatr Hematol Oncol 2018;40;e531-e6.
[35] Samson KLI, McCartney H, Vercauteren SM, Wu JK, Crystal DK. Prevalence of vitamin D deficiency varies widely by season in Canadian children and adolescents with sickle cell disease. J Clin Med 2018;7;14.

[36] Winters AC, Kethman W, Kruse-Jarres R, Kanter J. Vitamin D insufficiency is a frequent finding in pediatric and adult patients with sickle cell disease and correlates with markers of cell turnover. J Nutr Disorders Ther 2014;4;140.

[37] AlJama A, AlKhalifah M, Al-Dabbous IA, Alqudaihi G. Vitamin $\mathrm{D}$ deficiency in sickle cell disease patients in the Eastern Province of Saudi Arabia. Ann Saudi Med 2018;38;130-6.

[38] Garadah TS, Jaradat AA, Alalawi ME, Hassan AB. Hormonal and echocardiographic abnormalities in adult patients with sickle-cell anemia in Bahrain. J Blood Med 2016;7;283-9.

[39] Bakri AH, Garadah TS, Jaradadat AA, Al Ajmi A, Alawi ME, Sequeira RP. Prevalence of vitamin D deficiency in patients with sickle cell disease in Bahrain. Int J Med 2013;1;23-8.

[40] Gupta M, Katariya D. Status of vitamin-D deficiency in sickle cell disease in adults. J Evidence Based Med Healthcare 2018;5;3137-43.

[41] Mohammed S, Addae S, Suleiman S, Adzaku F, Annobil S, Kaddoumi O, et al. Serum calcium, parathyroid hormone, and vitamin D status in children and young adults with sickle cell disease. Ann Clin Biochem 1993;30;45-51.

[42] Bordbar MR, Haghpanah S, Zarei T, Dabbaghmanesh MH, Omrani GR, Saki F. Evaluation of bone mineral density in children with sickle-cell anemia and its associated factors in the south of Iran: a case-control study. Arch Osteoporos 2017;12;70.

[43] Chapelon E, Garabedian M, Brousse V, Souberbielle JC, Bresson $\mathrm{JL}$, de Montalembert M. Osteopenia and vitamin D deficiency in children with sickle cell disease. Eur J Haematol 2009;83;572-8.

[44] Mandese V, Bigi E, Bruzzi P, Palazzi G, Predieri B, Lucaccioni $\mathrm{L}$, et al. Endocrine and metabolic complications in children and adolescents with sickle cell disease: an Italian cohort study. BMC Pediatr 2019;19;56.

[45] Ozen S, Unal S, Erçetin N, Taşdelen B. Frequency and risk factors of endocrine complications in Turkish children and adolescents with sickle cell anemia. Turk J Haematol 2013;30;25-31.

[46] Arlet JB, Courbebaisse M, Chatellier G, Eladari D, Souberbielle JC, Friedlander G, et al. Relationship between vitamin D deficiency and bone fragility in sickle cell disease: a cohort study of 56 adults. Bone 2013;52;206-11.

[47] Garrido C, Cela E, Beléndez C, Mata C, Huerta J. Status of vitamin D in children with sickle cell disease living in Madrid, Spain. Eur J Pediatr 2012;171;1793-8.

[48] Akinlade KS, Atere AD, Rahamon SK, Olaniyi JA, Ogundeji PS. Vitamin D, bilirubin and urinary albumin-creatinine ratio in adults with sickle cell anaemia. Arch Bas App Med 2014;2;77-82.

[49] Hamdy M, Salama N, Maher G, Elrefaee A. Vitamin D and nonskeletal complications among Egyptian sickle cell disease patients. Adv Hematol 2018;2018;3867283.

[50] Tayo BO, Akingbola TS, Salako BL, McKenzie CA, Reid M, Layden J, et al. Vitamin D levels are low in adult patients with sickle cell disease in Jamaica and West Africa. BMC Hematol 2014;14;12.

[51] Adegoke SA, Figueiredo MS, Adekile AD, Braga JAP. Comparative study of the growth and nutritional status of Brazilian and Nigerian school-aged children with sickle cell disease. Int Health 2017;9;327-34. 